\title{
Information and participation in decision-making about treatment: a qualitative study of the perceptions and preferences of patients with rheumatoid arthritis
}

\author{
J Schildmann, ${ }^{1,2}$ M Grunke, ${ }^{3}$ J R Kalden, ${ }^{4}$ J Vollmann ${ }^{1}$
}

${ }^{1}$ Institute for Medical Ethics and History of Medicine, Ruhr University Bochum, Bochum, Germany; ${ }^{2}$ Department of Hematology, Oncology and Tumor Immunology, RobertRoessle-Clinic at the HELIOS Klinikum Berlin, Charite Medical School, Berlin, Germany; ${ }^{3}$ Unit for Rheumatology/Clinical Trials, University of Munich, Munich, Germany; ${ }^{4}$ Department of Medicine III, Friedrich Alexander University Erlangen-Nuremberg, Erlangen, Germany

\section{Correspondence to:}

Dr med Jan Schildmann Abteilung für Medizinische Ethik und Geschichte der Medizin, Ruhr-Universität Bochum, Malakowturm-Markstr 258a D-44799 Bochum, Germany; jan.schildmann@rub.de

Received 14 November 2007 Revised 2 March 2008 Accepted 18 March 2008

\section{ABSTRACT}

Objectives: To elicit the perceptions and preferences of patients with rheumatoid arthritis regarding information and participation in treatment decision-making. To analyse the patients' narratives on the background of the ethical discourse on various approaches to treatment decisionmaking.

Design: In-depth interviews with themes identified using principles of grounded theory.

Participants: 22 patients with long-standing rheumatoid arthritis.

Main outcome measures: Qualitative data on patients' perceptions and preferences regarding information and participation in decision-making about treatment.

Results: Decision-making about treatment has been described by the patients as a process consisting of different stages with shifting loci of control and responsibility. Patients initially received one treatment recommendation and were not aware of alternative treatment options. Those participants in this study who wanted information about negative effects of a treatment cited "interest in one's own health" and the potential "use of information" as reasons for their preference. The physicians' expert knowledge and clinical experience regarding the effects of medication were cited as arguments by patients for a treatment recommendation. Conclusions: The patients' accounts of decision-making about treatment differ from models of physician-patient relationship that have been put forward in ethical discourse. These differences may be relevant with respect to the starting point of an ethical analysis of treatment decision-making. Patients' accounts with respect to a lack of information on treatment alternatives point to ethically relevant challenges regarding treatment decision-making in clinical practice.

Information and patients' right to self-determination have been central aspects of the ethicolegal debate on decision-making in medicine during recent decades. The emphasis on individual preferences and the demand for respect for the rights of citizens-also regarding decisions about treatment-has led to the ideal of informed decisionmaking. Patients should be empowered by information about their diagnosis, treatment options and prognosis to make treatment decisions that correspond to their preferences and values. ${ }^{12}$ This approach to decision-making stands in contrast to the traditional, paternalistic model of decisionmaking, according to which physicians make treatment decisions based on their knowledge and views with respect to the best medical treatment for a patient.

In the past two decades, the model of informed decision-making has been increasingly criticised. It has been argued that the model of the informed decision reduces the role of physicians to technicians who, according to this model, should use their knowledge and skills to implement patients' wishes. Thereby the values of the medical profession no longer form part of the treatment decisionmaking process. ${ }^{3}{ }^{4}$ Another line of argument uses the results of empirical research according to which the quantity and complexity of information may overburden a significant proportion of patients. ${ }^{45}$

Various authors have proposed alternatives to the models of paternalistic and informed decisionmaking, taking into account the possible roles of patient and physician and other criteria relevant to distinguish the various approaches to medical decision-making. ${ }^{467}$ Table 1 summarises the characteristics of four often-cited models of the physician-patient relationship as put forward by Emanuel and Emanuel.

Empirical studies on information and participation in decision-making about treatment so far have focused on eliciting patients' preferences by means of quantitative methods. ${ }^{58}$ There is a scarcity of qualitative studies that explore patients' perceptions of decision-making and the underlying reasons for their information and participation preferences. ${ }^{49}$ Detailed descriptions of decisionmaking in medicine can serve as a starting point for ethical analysis. In addition, data about patients' preferences and their reasons for them inform the debate about ethical aspects of decision-making about treatment from the perspective of a party affected by the decision.

This qualitative study presents the findings of semistructured interviews regarding the perceptions and preferences of 22 patients with longstanding rheumatoid arthritis concerning treatment decisions.

The aims were to elicit from patients with rheumatoid arthritis:

- an account of the perceptions regarding decision-making about medication;

- their preferences regarding information in the context of decision-making about medical treatment, and the reasons for these preferences;

- their preferences with respect to participation in the decision. 
Table 1 Key characteristics of medical decision-making models ${ }^{3}$

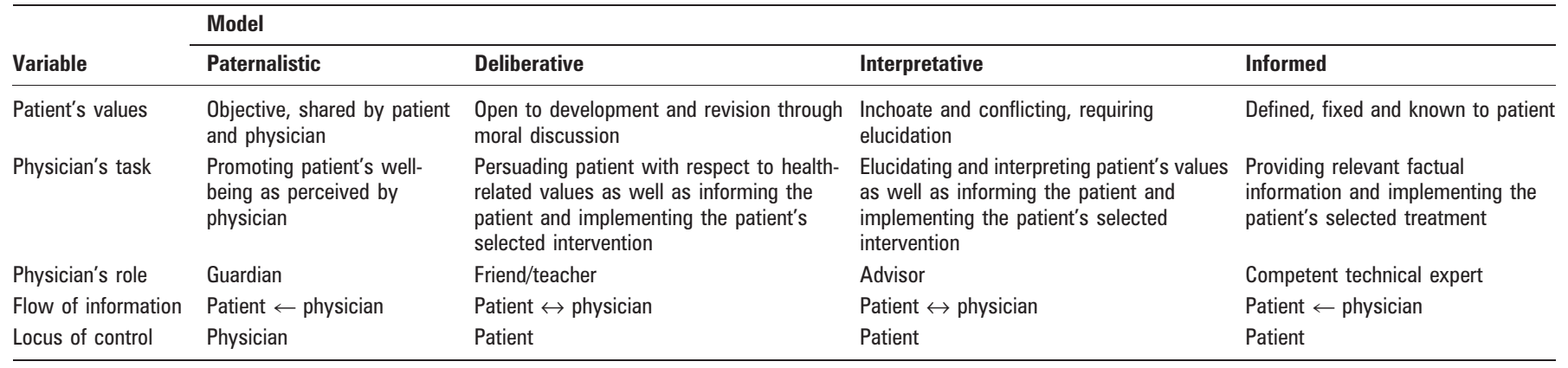

Our results are discussed with reference to the various models of physician-patient interaction that have been advanced in the discussion about ethically acceptable approaches to treatment decision-making as well as relevant empirical findings.

\section{PARTICIPANTS AND METHODS Participants and procedures}

In accordance with the vote of the research ethics committee of the Medical Faculty of the University Erlangen-Nuremberg (Germany), patients were invited to participate in the study by the physicians working in the outpatient clinic of the University Hospital Erlangen. Inclusion criteria were a diagnosis of rheumatoid arthritis according to the definition of the American College of Rheumatology, a sequence of at least two therapeutic regimens and the ability to speak German. In accordance with the current guidelines for the management of rheumatoid arthritis, patients at this stage may be treated with any of a variety of substances. ${ }^{10}$

The sampling strategy consisted of recruitment of patients who consecutively visited the outpatient clinic of the university hospital and who had been considered as potential participants by their physicians. In addition to this convenience sample, the interviewer (JS) pointed out characteristics that should be considered by the clinicians when approaching potential participants for the study (theoretical sampling-for example, maximum variation sampling). Written informed consent was elicited by the interviewer. Semistructured interviews were conducted on the basis of an interview guide (see appendix) and audiotaped. Demographic data were collected by self report. Interviews were scheduled in patients' homes or in an office of the university hospital, depending on the patients' choice.

\section{Data analysis}

Interview transcripts were analysed according to principles of grounded theory as described by Strauss and Corbin. ${ }^{11}$ Grounded theory consists in a set of analytical techniques that were originally designed for the purpose of sociological enquiry. Like other qualitative methods, it is used to explore data with a critical awareness of assumptions and theoretical preconceptions. The aims of this methodological approach may be described as the generation of new concepts, hypotheses and, if possible, new-empirically grounded-theories relevant to a research topic, which emerge as a result of the iterative process of data analysis and data interpretation.

In this study, essential principles of grounded theorynamely the constant comparison of data, open coding, writing memos and theoretical sampling-have been used to explore patients' perceptions and preferences regarding treatment decision-making. After verbatim transcription of the audiotaped interviews and a check of data, all transcripts were analysed by the first author, sentence by sentence. Sections (sentences or small paragraphs) of the first transcripts concerning patients' perceptions and preferences with respect to treatment decision-making were selected and labeled with a code (a word or phrase). The codes express the content of the analysed data as understood and conceptualised by the researcher in the light of the research focus (open coding). After the iterative process of data gathering and data analysis and the process of constant comparison of data, similar concepts were merged into more abstract categories. To illustrate the conceptualisation of data, quotes from the interviews were selected and allocated to categories derived from the data.

To gain a sample with a maximum variation of characteristics that may be relevant to the research topic, the sampling of participants was based on considerations of factors known to influence the narratives of the patients (eg, education, gender, age) (theoretical sampling). ${ }^{11}$ By writing memos, we were able to be as transparent and reflective as possible regarding decisions made during the process of data gathering and interpretation. To reduce interpretative bias, we regularly discussed among ourselves the transcripts of the interviews and the drafts of the data analysis. In addition, transcripts and preliminary interpretations were presented at interdisciplinary meetings every 2 weeks between the first author and two other researchers who were also conducting qualitative research projects. The presentation of preliminary findings at several interdisciplinary conferences and discussions about the interpretation of data among the authors during the drafting of this paper were additional occasions on which data analysis and interpretation was critically reviewed. The enrolment of participants was stopped once the analysis of the most recent interviews did not generate new codes or enrich existing categories (theoretical saturation).

\section{RESULTS \\ Participants}

Twenty-two patients were invited to participate in the study, all of whom agreed to take part and be interviewed. Their mean age was 56.9 years ( 19 women and 3 men); all had public health insurance. Further information about the sample of participants is provided in table 2 .

\section{Perceptions of decision-making about medical treatment}

The narratives of interviewees regarding their perceptions of medical treatment decision could be interpreted as a four-stage process (table 3 ). The initial stage has been descibed by participants as brief discussions with their physicians about a new treatment. Physicians recommended a specific treatment and patients perceived the situation at this stage of the 
Table 2 Demographic data of patients participating in the study

\begin{tabular}{lc}
\hline Variable & Number \\
\hline Gender & \\
$\quad$ Female & 19 \\
Male & 3 \\
Education & \\
Elementary school (Haupt- or Volksschule) & 11 \\
Secondary school (Realschule) & 5 \\
German university entrance qualification (Abitur) & 4 \\
No information & 2 \\
Nationality & \\
German & 20 \\
Other & 2
\end{tabular}

$\mathrm{N}=22$.

decision-making process as one where there was no treatment alternative. Interviewer: "When you were discussing a new treatment, did the doctor ever ask you what was important to you concerning the treatment ...?" Patient: "No, he didn't ask me, but he said something about side effects and how long it would take, and that we need to change something if things get inconvenient [...]. So I just said, well, then we must try it. There are no alternatives, there was no alternative" (patient 9).

Three different types of response of the patients to a treatment recommendation by the physician were identified:

- Consent: This type of response was characterised by consent to the proposed medication without any further discussion. As reasons for this type of reaction patients cited a lack of medical knowledge and a hope that health would improve after the recommended treatment: "I relied on the physicians to give me the right recommendation [...] he had recommended this to me, told me that I should try it and so I did" (patient 2).

- Discussion: This category was characterised by patients' asking questions about positive and negative effects of the proposed medication and about alternatives. "I always ask for options, what [treatment] might be possible for me [...]; that was the way I did it and that was the way the dialogue with the doctor went" (patient 13).

- Veto: This type of response was characterised by rejection of the recommended treatment. Patients feared negative effects either because of earlier experiences with the proposed medication or based on theoretical knowledge about possible adverse effects. According to the patients, the rejection of a recommended treatment led to another treatment recommendation by the physician. "[...] and then came Remicade [...] that would have been not bad but it affects my vision and I hardly see anything with my right eye so I did not want it [...] and then we started with Arava" (patient 5).
During a third stage of the decision-making process ("testing of medication"; see table 3), patients gathered experiences with the recommended medical treatment. As a consequence, participants in this study reported situations in which they had to stop the treatment because of unacceptable effects of the medication: "And then I was feeling really bad, I simply couldn't tolerate it. I had nausea and although the doctor, I can not remember her name, was very sorry I had to break it off" (patient 2).

The final stage of decision-making has been described as one in which physicians and patients exchanged their evaluations of the treatment decision: "When I had the feeling that I was not well, then I said, tell me, is there something else? Or when I was feeling well but the blood tests were bad, then the doctor said, well, now we should add this and that. I think this was like a partnership somehow" (patient 12).

\section{Preferences regarding information and participation in medical decision-making}

In this study, all but two patients preferred to be informed about possible negative effects. "Interest in one's own health" and "use of information" were identified as two categories summarising the rationale underlying the preference for information about possible negative effects.

- Interest in one's own health: The fact that it is the patients' "own health" that is affected by the treatment was cited as one argument in favour of information about possible negative effects: "Well, you know, it's important for me to know what kind of medication it is [...], the side effects, you know, what might happen. I'm curious and so I also read about it, you know, it is about my health" (patient 10).

- Use of information: Patients argued that knowledge about the potential risks of a medication enabled them to identify negative effects as possible causes of the new treatment. This again allowed them to react to any changes experienced-for example, by modifying the dosage or by taking additional medication in order to counteract the negative effects: "All medication has side effects, and then you must know how to protect yourself against it" (patient 9).

Two patients in this study were hardly or not at all interested in information about possible negative effects of a recommended treatment. These patients argued that first, such knowledge might create anxiety concerning the realisation of possible negative effects and that, second, medical treatment was necessary to improve their state of health. Therefore, information about potential risks would not have any consequences: "I think you should at least be a little informed, and obviously you know that any medication has negative effects, but I don't want to know about that in detail. If an operation comes up, then he [the physician] says that he must

Table 3 Stages of the process of deciding on treatment, as perceived by patients with rheumatoid arthritis

\begin{tabular}{|c|c|c|c|c|}
\hline Participant & $\begin{array}{l}\text { Stage } 1 \\
\text { Recommendation of treatment }\end{array}$ & $\begin{array}{l}\text { Stage } 2 \\
\text { Response }\end{array}$ & $\begin{array}{l}\text { Stage } 3 \\
\text { Testing of medication }\end{array}$ & $\begin{array}{l}\text { Stage } 4 \\
\text { Evaluation of treatment decision }\end{array}$ \\
\hline Patient & $\begin{array}{l}\text { Description of signs and } \\
\text { symptoms }\end{array}$ & $\begin{array}{l}\text { (a) Consent } \\
\text { (b) Discussion }\end{array}$ & $\begin{array}{l}\text { Gathering of experience with } \\
\text { medication }\end{array}$ & $\begin{array}{l}\text { Evaluation of treatment based on subjective } \\
\text { perceptions }\end{array}$ \\
\hline
\end{tabular}

(c) Veto

Decision about medication (eg, to stop treatment or to modify dosage)

\begin{tabular}{|c|c|c|}
\hline Physician & Recommendation of treatment & $\begin{array}{l}\text { (a) Prescription } \\
\text { (b) Explanation } \\
\text { (c) Recommendation of an } \\
\text { alternative }\end{array}$ \\
\hline
\end{tabular}

Giving feedback to physician

Evaluation of treatment based on objective and subjective parameters 
inform me that you might not wake up any more and what might happen to you because of the anaesthesia, and I always say I don't want to know about that [...]. I need to have it done anyway." Interviewer: "And why don't you want to know it?" Patient: "I think this causes even more anxiety" (patient 5).

All patients favoured a treatment recommendation by their physicians. The physician's expert knowledge, clinical experience with the medication and perception of the state of health of a patient were cited as arguments in favour of treatment recommendations: "Yes, because I think if he recommends it, then he has experience with it and then he can tell me from his experience that it has helped a lot of other patients and, well, how it will work with me, that I must try it myself" (patient 7).

\section{DISCUSSION}

\section{Selection of participants and method}

This qualitative study provides an account of the perceptions and preferences of patients with rheumatoid arthritis regarding decision-making about medical treatment. According to current guidelines, patients with rheumatoid arthritis may be treated with a variety of substances, including non-steroidal antiinflammatory drugs, corticosteroids, disease-modifying antirheumatic drugs or biologic agents. The different treatment approaches vary with respect to the approximate time to benefit, dosage and mode of application (eg, oral, subcutaneous, intravenous), potential negative effects and risks that need regular monitoring, and costs. ${ }^{10}$ Against this clinical background, patients with rheumatoid arthritis provide a good model for the investigatation of patients' perceptions and preferences in situations of decision-making in which there is more than one choice of medical treatment.

Because our sample is not representative of the group of patients with rheumatoid arthritis, the results cannot be generalised to all patients with the disease. The patients were invited by their physicians, so there may have been a selection bias. Therefore, the views elicited in this study may not cover the whole range of views of patients with rheumatoid arthritis. In addition, selective memory, socially desirable answers and the influence of positive or negative effects of the treatment experienced are possible factors that may have influenced the perceptions and preferences of patients stated in the interviews.

One advantage of the qualitative approach and the rationale for using it in this study is the possibility of gaining in-depth information about patients' perceptions of decision-making regarding medical treatment. ${ }^{12}$ This approach allows an empirically based reconstruction of the decision-making process as perceived by the patients taking part. It thereby provides a heuristic basis for the construction of research instruments in future quantitative studies in which the perceptions and views of patients with various illnesses regarding information and participation in medical treatment may be investigated. A second advantage is that the results of the interpretation of data can be used for a comparative analysis between the empirically based findings and theoretical models of treatment decisionmaking put forward in the literature. Finally, the semistructured approach allowed the researcher to elicit patients' preferences regarding information and participation in decision-making and also to explore the underlying reasons. The research can thereby inform the debate on ethical approaches to decision-making using the perspective of one group of patients.

\section{Perceptions of decision-making about medical treatment}

The reconstruction of the narratives of patients emphasises a procedural character of decision-making about treatment, as has been pointed out in earlier sociological research. ${ }^{13}$ Decisionmaking about treatment, as viewed by the patients, is not a single event but is, rather, a sequence of decisions. Patients initially respond to treatment suggestions by their physicians, whereas in the later stages of the decision-making process they make their own decisions-for example, modifying the dosage or stopping the treatment or re-evaluating the treatment together with their physician. The reconstructed model of treatment decision-making provides a specific, detailed perspective on the interaction between patient and physician and thereby furthers the understanding of the process. The detailed accounts with respect to the various stages of the decisionmaking are relevant for the ethical analysis in so far as it is the basis for a concept of shifting loci of control during the process of decision-making about treatment. According to this view of decision-making, it is neither only the patient nor only the physician who makes decisions; rather, both parties contribute to the process at different stages with different intensities. This view of the dynamics of the decision-making process is not well reflected by models on decision-making-such as the models of paternalistic or informative decision-making-according to which, control for the decision rests either with the patient or with the physician. While intermediate models, such as the deliberative models, leave some room for dynamics with respect to influence and control of decision-making on the part of patients as well as physicians, the reconstructed model adds a more detailed perspective with respect to different stages of the decision-making process. In addition to their relevance as a starting point for ethical analysis, patients' perceptions of treatment decision-making as a process also seem relevant to ethically appropriate conduct in clinical practice. As pointed out, the interviewees in this study perceived follow-up visits as an important occasion on which to air their experiences with the recommended treatment. At this stage, they perceived decision-making more as a partnership, which differs from the perceptions regarding the initial stage of decision-making and which requires skills of physicians to adapt their approach to decision-making.

Various views of decision-making contribute to the debate on ethical aspects of the patient-physician relationship, in the sense that different descriptions of the decision-making may change the starting point for the ethical analysis. The account of decision-making put forward in this paper is based on the narratives of one patient group, and interviews with other groups of patients or physicians might offer different perspectives on decision-making about medical treatment.

Participants in our study reported that they had received little information about various treatment options when discussing new medication with their physicians. Instead, physicians routinely informed their patients only about the treatment they would recommend. This finding agrees with results from other interview studies and from observational studies. ${ }^{14}{ }^{15}$ The preselection of treatment options without naming alternatives seems problematic for at least two reasons: first, patients are restricted in exercising their right to self-determination if they are not informed about the spectrum of existing treatment options. Second, this preselection may also violate the principles of beneficence and non-maleficence, because different treatment options may further the well-being of patients more or less, depending on the patients' individual values and preferences. ${ }^{16}$ 


\section{Preferences regarding information and participation in decision- making about treatment}

All but two patients wished to be informed about potential adverse effects of a treatment. "Interest in one's own health" and the possible "use of information" were identified as factors generating patients' demand for information. In the literature, information has been often discussed as a prerequisite to exercising the right to self-determination and to making an autonomous decision. ${ }^{4}{ }^{17}$ The analysis of the interviews suggests that other reasons than the use of information to make an autonomous decision play an important role in patients' preferences for information. This finding of the study may provide an explanation for the divergent results of quantitative studies, which indicate that patients want to be informed, but that only to a lesser degree do they wish to share responsibility in healthcare decisions. ${ }^{5}$

All the patients interviewed in this study wanted a treatment recommendation by their physician, giving as their reason a selfperceived lack of theoretical and practical expertise concerning the available treatment options. In this respect, the preferences expressed by the interviewees fit with an understanding of the role of the physician as "friend" or "teacher", as has been suggested in the model of deliberative decision-making. ${ }^{3}$ This concept of the patient-physician relationship does take into account that decision-making between the two parties may appropriately involve value judgments on the part of the physician-for example, with respect to the risks and benefits of a treatment option. While recommendation of a treatment has been criticised as unduly influencing patients, we would argue in favour of it. First, it is questionable whether it is theoretically even possible to make a strict fact value distinction, much less to implement such an approach as part of the communication process between patients and physicians. ${ }^{18}$ Second, data from representative quantitative studies show that most patients want such recommendations, and in this sense to give such guidance is to respect patients' expressed wishes. ${ }^{5}$ Finally, it could be argued that an autonomous decision is not one that is based on descriptive information only, but is one that has been made also in the light of interpretation and value judgements of other persons. A prequisite for such an ideal of decision-making is, of course, that physicians provide detailed information including treatment alternatives and also are reflective and transparent with respect to their value judgements.

\begin{abstract}
Acknowledgements: We would like to thank all the patients who took part for their willingness to share their perspectives and preferences with respect to treatment decision-making. We also would like to thank Dr P Terzioglu, Dr W Vogd, Dr S Heddenig, Dr N Burchardi and Mr S Siegel for the discussions on methodological aspects and the results of this research. The authors would also like to thank the ELAN-Fonds (University Hospital Erlangen) for its support of this interdisciplinary research project. An earlier draft of this paper was awarded a Prize of the European Society for Philosophy of Medicine and Health Care.
\end{abstract}

Competing interests: None.

\section{REFERENCES}

1. Kassirer JP. Incorporating patients' preferences into medical decisions. N Eng/ J Med 1994;330:1895-6.

2. Veatch R. Abandoning informed consent. Hastings Cent Rep 1995 25:5-12.

3. Emanuel EJ, Emanuel LL. Four models of physician-patient relationship. JAMA 1992;267:2221-6.

4. Charles C, Gafni A, Whelan T. Shared decision-making in the medical encounter: what does it mean? (or it takes at least two to tango). Soc Sci Med 1997:44:681-92.
5. Frosch DL, Kaplan RM. Shared decision making in clinical medicine: past research and future directions. Am J Prev Med 1999;17:285-94.

6. Brody DS. The patient's role in clinical decision-making. Ann Intern Med 1980:93:718-22.

7. Siegler $\mathbf{M}$. The progression of medicine. From physician paternalism to patient autonomy to bureaucratic parsimony. Arch Intern Med 1985;145:713-5.

8. Vollmann J. Aufklärung und Einwilligung in der Psychiatrie. Ein Beitrag zur Ethik in der Medizin [Informed consent in psychiatry. A contribution to medical ethics]. (In German.) Darmstadt: Steinkopff Verlag, 2000.

9. Say R, Murtagh M, Thomson R. Patients' preferences for involvement in medical decision making: a narrative review. Patient Educ Couns 2006;60:102-14.

10. American College of Rheumatology Subcommittee on Rheumatoid Arthritis Guidelines. Guidelines for the management of rheumatoid arthritis: 2002 update. Arthritis Rheum 2002;46:328-46.

11. Strauss A, Corbin J. Grounded theory: Grundlagen qualitativer Sozialforschung [Grounded theory: basics of qualitative social research]. (In German.) Weinheim: Psychologie Verlags Union, 1996.

12. Giacomini M, Cook D. Users' guides to the medical literature: XXIII. Qualitative research in health care $B$. What are the results and how do they help me care for my patients? JAMA 2000;284:478-82.

13. Kirschning S. Brustkrebs. Der Diagnoseprozess und die laute Sprachlosigkeit der Medizin. Eine soziologische Untersuchung [The process of diagnosis and the loud speechlessness of medicine. a sociological study]. (In German.) Leverkusen: Leske und Budrich, 2001.

14. Schildmann J, Bauer A, Tilmann A, et al. Aufklärung und Einwilligung zur Psychopharmakotherapie aus der Sicht schizophrener und depressiver Patienten. Eine empirische Untersuchung aus der klinischen Medizinethik. [Patients' perspective on the quality of informed consent into psychopharmacological treatment in schizophrenia and depression]. (In German.) Fortschr Neurol Psychiatr 2003;71:265-70.

15. Wu WC, Pearlman RA. Consent in medical decision making: the role of communication. J Gen Intern Med 1988:3:9-14.

16. Anselm R. Jenseits von Laienmedizin und hippokratischem Paternalismus. Theologisch-ethische Überlegungen zum Problem der Selbstbestimmung in der Medizin [Beyond lay medicine and Hippocratic paternalism. Theologic-ethical reflection on the problem of self-determination in medicine]. (In German.) Z Med Ethik 1999:45:91-108.

17. Joffe S, Manocchia M, Weeks JC, et al. What do patients value in their hospital care? An empirical perspective on autonomy centred bioethics. J Med Ethics 2003;29:103-8.

18. Brock DW. The ideal of shared decision making between physicians and patients [review]. Kennedy Inst Ethics 1991;1:28-47.

\section{APPENDIX}

\section{Interview guide (translated version)}

\section{Perception of treatment decision-making}

Question $1 \mathrm{Mr} / \mathrm{Mrs}$... , first of all I would be interested to hear about what happened after you had heard about the fact that you have rheumatoid arthritis?

Clarify

- What kind of information about suggested treatment was received?

- What kind of information did your physicians want in the context of treatment decision-making?

- Any preferences on the part of your physician with respect to treatment?

- Any treatment alternatives suggested?

- Who took part in discussions about treatment?

- Any discussions about treatment with persons other than your physician (friends, family, other patients, etc)?

- Any information resources about illness and treatment options leg internet, television)?

\section{Preferences regarding information and participation in decision-making}

Question 2 What was important to you when discussing a new treatment for your illness?

Clarify

- Satisfied with level of information/participation?

- Wish to be informed about treatment? Why (not)?

- Interest in specific information about treatment? Why?

- Wish to get treatment recommendation? Why (not)?

\section{Demographic data}

Age, gender, education, insurance, beginning of illness, nationality. 


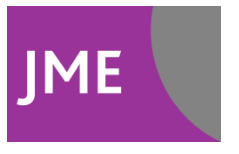

\section{Information and participation in decision-making about treatment: a qualitative study of the perceptions and preferences of patients with rheumatoid arthritis}

J Schildmann, M Grunke, J R Kalden, et al.

$J$ Med Ethics 2008 34: 775-779

doi: 10.1136/jme.2007.023705

Updated information and services can be found at:

http://jme.bmj.com/content/34/11/775.full.html

These include:

References This article cites 15 articles, 1 of which can be accessed free at: http://jme.bmj.com/content/34/11/775.full.html\#ref-list-1

Article cited in:

http://jme.bmj.com/content/34/11/775.full.html\#related-urls

Email alerting Receive free email alerts when new articles cite this article. Sign up in service the box at the top right corner of the online article.

Topic Articles on similar topics can be found in the following collections Collections Research and publication ethics (417 articles)

Notes

To request permissions go to:

http://group.bmj.com/group/rights-licensing/permissions

To order reprints go to:

http://journals.bmj.com/cgi/reprintform

To subscribe to BMJ go to:

http://group.bmj.com/subscribe/ 